\title{
ACTIVATED CARBON FROM BAMBOO WASTE: EFFECT OF ACTIVATION SEQUENCES AND IRON-COBALT IMPREGNATION TO MATERIAL PROPERTIES AND CATALYST PERFORMANCE
}

\author{
Jimmy Jimmy, Achmad Roesyadi*, Suprapto Suprapto, Firman Kurniawansyah, \\ Warih Anggraini, Rizka Rahmawati \\ Institut Teknologi Sepuluh Nopember, Indonesia
}

Bamboo "Ori" (Bambusa blumeana) is a potential raw material for activated carbon production due to rapid growth and abundant availability. Raschig ring activated carbon for industrial catalyst, catalyst support and adsorbent in purification process can be made from small diameter bamboo branches. The activated carbon as a support for Fe and Co catalysts in Fischer-Tropsch synthesis provides an opportunity for direct conversion from synthesis gas (CO and $\left.\mathrm{H}_{2}\right)$ to biofuel $\left(\mathrm{C}_{5}-\mathrm{C}_{19}\right)$. The effect of activation sequence on the activated carbon and impregnation product properties was investigated. Activated carbon was obtained from bamboo waste through various activation sequences (steam, phosphoric acid and carbonization), then it was impregnated with 10\% metal loading. The Fe composition in the initial metal mixture was varied at 0-40\% from total composition. After impregnation, reduction was applied by flowing hydrogen gas at $400^{\circ} \mathrm{C}$ for 10 hours. These catalysts were performed for Fischer-Tropsch synthesis in a batch reactors. The activation sequences of carbonization-acid and acid-carbonization gave similar surface area (2173 and $2091 \mathrm{~m}^{2} / \mathrm{g}$ ), much greater than the steam-carbonization-acid and steam-acid-carbonization (427 and 478 $\mathrm{m}^{2} / \mathrm{g}$ ) sequences. Functionalization with nitric acid produced oxygen functional groups of carboxyl, carbonyl, alcohol and phenol.Catalyst reduction gave $\mathrm{Fe}$, $\mathrm{Co}$ and $\mathrm{Fe}$-Co alloys as active metal and a little oxides $\mathrm{Fe}_{2} \mathrm{O}_{3}$ and $\mathrm{Co}_{3} \mathrm{O}_{4}$. The larger amount of Fe-Co alloys were formed on 30Fe-70Co/Activated Carbon and 40Fe-60Co/Activated Carbon catalyst. Fischer-Tropsch synthes is was performed in batch at $\mathrm{H}_{2} \mathrm{CO}=2, \mathrm{Fe}-\mathrm{Co} /$ Activated Carbon catalyst, $250^{\circ} \mathrm{C}, 8$ bars for 18 hours. The n-paraffin compound is only formed in 40Fe-60Co/Activated Carbon catalyst which contained the highest amount of Fe-Co alloys. The more Fe-Co alloys content was, more n-paraffin was formed. The $n$-paraffin $(\mathrm{OH})$ compound was only formed in 10Fe-90Co/AC. The more Co content was, more n-paraffin (OH) was formed.

Key words: bamboo waste, activation sequences, activated carbon, functionalization, iron-cobalt composition

\section{INTRODUCTION}

Silica, alumina and titania that are widely used in Fischer-Tropsch synthesis (FTS) provide strong metal-support interactions for $\mathrm{Fe}$ and Co catalysts which cause permanent catalyst deactivation [1]. The use of carbon support is recommended to overcome this problem [2]. Various studies for carbon material in FTS encourage other researchers to explore the fundamental concept of carbon in its role as a catalyst support and as a catalyst itself. Carbon material can be considered as a new support in the Fischer-Tropsch reaction because of its unique properties such as uniform pore size distribution, micropore and mesopore structure, inert surface properties and resistance to alkaline and acidic environments $[3,4]$. Activated carbon (AC) was a better catalyst support system for production of $\mathrm{C}_{5}-\mathrm{C}_{10}$ hydrocarbons (up to $66 \%$ ) than carbon nanotubes and mesoporous carbon. The $\mathrm{C}_{11}-\mathrm{C}_{17}$ fraction was also quite high (up to $30 \%$ ). This results gave promising biofuel fraction produced from activated carbon as catalyst support [5].

Bamboo waste is a cheap potential feedstock for the production of activated carbon material. This material can be obtained from small bamboo branch, found at the top of bamboo tree. Bamboo handicraft productions also produce waste,that can be converted to powder activated carbon. The performance of metal catalysts with activated carbon support is affected by bamboo material size, activation agent, carbonization conditions, activation sequence, functionalization, impregnation method, type of metal catalyst, loading of metal mixtures on activated carbon and reduction. The carbonization process was carried out at $400-900^{\circ} \mathrm{C}$ for $2-4$ hours using physical activation (steam) and chemical activation (different activation agents were used, including phosphoric acid, hydrochloric acid, nitric acid, sodium hydroxide, and potassium hydroxide) [6-10]. The phosphoric acid treatment as an activation agent gave best results [7-9]. Carbon material is inert, but contains functional groups attached to the surface. Functional groups can also be created as needed with various types of functionalization agents. Oxygen groups, such as carboxyl groups, lactone, hydroxyl, quinone, ether, pyrone, carboxylic anhydride, chromene, lactol and $\pi$ electron density on carbon basal planes, are most commonly found on carbon surfaces [11]. Functionalization of activated carbon using $28 \%$ nitric acid solution at $80^{\circ} \mathrm{C}$ for 4 hours gave surface area $1897 \mathrm{~m}^{2} / \mathrm{g}$; pore volume $1.00 \mathrm{~cm}^{3} / \mathrm{g}$; pore size diameter of $0.9 \mathrm{~nm}$. The functionalized activated carbon was impregnated with $20 \%$ Co catalyst loading, 
then they produced catalyst material with a surface area of $854 \mathrm{~m}^{2} / \mathrm{g}$; pore volume of $0.44 \mathrm{~cm}^{3} / \mathrm{g} ; 1.4 \mathrm{~nm}$ pore size diameter [5].

The combination of $\mathrm{Fe}$ and Co catalyst (bimetal catalyst) with conventional supports $\mathrm{TiO}_{2}, \mathrm{Al}_{2} \mathrm{O}_{3}$ and $\mathrm{SiO}_{2}$, succeeded in increasing the reaction conversion and biofuel fraction compared to the use of Fe and Co catalysts separately [12-14]. Based on these two concepts, the combination of $\mathrm{Fe}$ and $\mathrm{Co}$ catalysts with activated carbon is expected to increase FTS effectiveness and efficiency. The study emphasized on studying the effect of activation sequence on the activated carbon and impregnated catalyst properties. FTS products could be used directly as vehicle fuel, because of identical chemical structure and properties with fossil fuel. This renewable energy is interesting to be further developed.

\section{MATERIALS AND METHODS}

This experiment used the small branch of bamboo "ori" (Bambusa blumeana), $\mathrm{Fe}\left(\mathrm{NO}_{3}\right)_{3} \cdot 9 \mathrm{H}_{2} \mathrm{O}$ (Merck), $\mathrm{Co}\left(\mathrm{NO}_{3}\right)_{2} \cdot 6 \mathrm{H}_{2} \mathrm{O}$ (Merck), phosphoric acid $85 \%$ (Merck), nitric acid p.a. (Merck), nitrogen gas (High Purity grade, PT Samator, Indonesia), hydrogen gas (High Purity grade, PT Samator, Indonesia) and synthesis gas (15\% $\left.\mathrm{CO}, 30 \% \mathrm{H}_{2}, 55 \% \mathrm{~N}_{2}\right)$. The methods were supported with furnace reactor (Figure 1), batch reactor, hotplate magnetic stirrer, vacuum filter, hot air oven, syringe, digital scales and standard glasswares.

The ring and powder activated carbon material were used in this research. The ring-shaped (Raschig ring) activated carbon was made from bamboo, 8-10 $\mathrm{mm}$ in diameter, $6 \mathrm{~mm}$ length. The powder activated carbon was 80-100 mesh. The activated carbon from bamboo was synthesized in various activation sequences, i.e. steam-carbonization-acid (P1), steam-acid-carbonization (P2), carbonization-acid (P3), acid-carbonization
(P4). Saturated steam at $105^{\circ} \mathrm{C}$ was used as physical activation agent that was applied at 1 bar for 2 hours. The carbonization process of $20 \mathrm{~g}$ bamboo ring was carried out on crucible at $500^{\circ} \mathrm{C}$ in flowing nitrogen for 2 hours in the tube furnace reactor (Figure 1). Phosporic acid was used as acid activation agent (1 gram of bamboo in $5 \mathrm{~mL}$ of acid solution), then stirred at $85^{\circ} \mathrm{C}$ for 1 hour, washed and dried. Activated carbon of P1, P2, P3, P4 were functionalized using $65 \%$ nitric acid solution. Impregnation of $\mathrm{Fe}$ and $\mathrm{Co}$ metal catalysts were carried out on ring and powder activated carbon. Wet impregnation was applied to ring activated carbon because the spray treatment in incipient wetness methods could not reach inner surface area in the ring structure Impregnation of $\mathrm{Fe}$ and Co metal catalysts on powder activated carbon was carried out by incipient wetness impregnation method because the powder shape will provide a more even distribution of metal catalyst solutions on the entire surface compared to ring activated carbon. $\mathrm{Co}\left(\mathrm{NO}_{3}\right)_{2} \cdot 6 \mathrm{H}_{2} \mathrm{O}$ and/or $\mathrm{Fe}\left(\mathrm{NO}_{3}\right)_{3} \cdot 9 \mathrm{H}_{2} \mathrm{O}$ solution were used as precursor. The amount of catalyst loading was $10 \%$ (weight) and iron composition were varied at $0-40 \%$ (weight). The impregnated sample was dried, calcined in flowing $\mathrm{N}_{2}$ at $500^{\circ} \mathrm{C}$ for 2 hours, then reduced with flowing $\mathrm{H}_{2}$ at $400^{\circ} \mathrm{C}$ for 5 hours. The activated carbon and catalyst properties were analyzed with Brunauer-Emmett-Teller (BET; Quantachrome ${ }^{\circledR}$ ASiQwin ${ }^{\mathrm{TM}}$; at Robotics Laboratory, ITS Surabaya), The BET model was used to analyze the volume and surface area of micropore and mesopore (deriving from t-plot data) [15] and the pore size distribution (deriving from Barrett, Joyner, and Halenda or BJH model) [16]. Methylene blue adsorption (spectrophotometry methods; at Chemical Reaction Engineering Laboratory, ITS Surabaya). The Surface area, diameter and pore volume were obtained from BET analysis which was validated using methylene blue absorption test. Methylene blue adsorption test is maximum amount of methylene

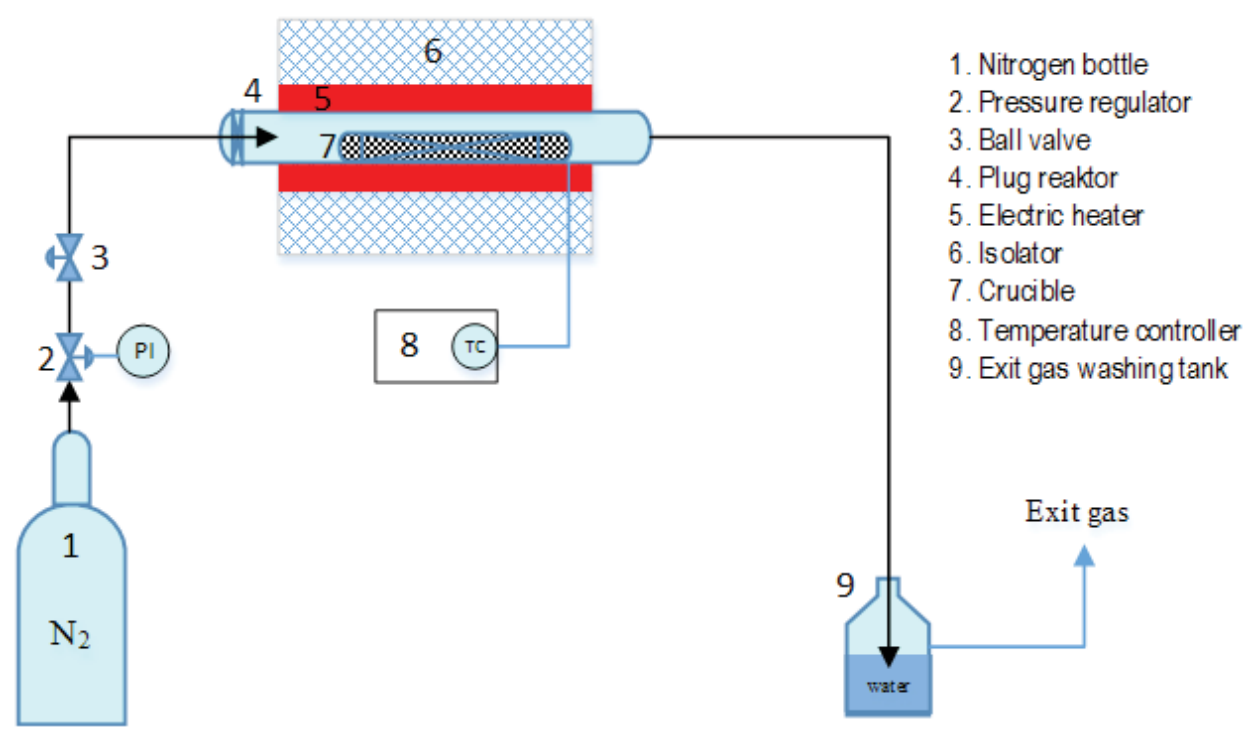

Figure 1: Tube furnace reactor (Linn Elektro Therm) for carbonization and reduction process in the Fe-Co/Activated Carbon catalyst synthesis 
blue adsorbed onto one gram of carbon. The more methylene blue adsorbed, indicated the greater surface area [17]. X-ray Diffraction (XRD; Philips X'Pert MPD system; at Material and Metallurgical Laboratory, ITS Surabaya), Energy Dispersive X-ray Spectroscopy (EDX; EDAX TSL Ametek; at Material and Metallurgical Laboratory, ITS Surabaya) and Fourier Transform Infrared spectroscopy (FTIR; IRAffinity-1S FTIR Spectrometer; at Chemistry Department Laboratory, ITS Surabaya).

For initial performance catalyst test, $2 \mathrm{~g}$ of catalysts were conducted into a batch of Fischer-Tropsch reaction at $250^{\circ} \mathrm{C}, 8$ bars for 18 hours. The liquid product was analyzed by Gas Chromatography - Mass Spectrometry (GC-MS; HP-Agilent 6890 FID System; Capillary Column: Agilent 19091S-433 HP-5MS; at PT. Gelora Djaja Laboratory, Surabaya).

\section{RESULTS AND DISCUSSION}

\section{Characteristics of activated carbon from bamboo}

The yields of activated carbon from bamboo waste in this studies depended on activation sequences $(P 1=28.00 \%$, $\mathrm{P} 2=37.00 \%, \mathrm{P} 3=38.50 \%$ and $\mathrm{P} 4=44.00 \%$ ). The yield functionalized activated carbons from bamboo waste were $8.36 \%$ of $P 1,25 \%$ of $P 2,21.50 \%$ of $P 3$ and $23.38 \%$ of $\mathrm{P} 4$ sequences. Steam activation treatment as applied on $\mathrm{P} 1$ gave the least yield. The others gave similar yield (in range of $21-25 \%$ yield from initial bamboo waste).

Surface area, pore size and functional groups are important parameters for activated carbon as catalyst support. Surface area, diameter and pore volume were obtained from BET analysis which was validated using methylene blue adsorption test (Table 1). The activation sequences affected the surface area of activated carbon formed. The combination of steam and acid activation (P1 and P2) produced very low surface area of activated carbon (Table 1). The steam activation stimulated swelling process that caused water absorption into the carbon structure. It probably restricted the pore size that had been formed, then which in turnre stricted the pore volume and decreased surface area. The swelling enlarged the carbon structure volume, then it reduced the pore volume. The carbonization and heating treatments did not change pore volume and surface area. The largest surface area of activated carbon was obtained in the activation sequencesof P3 and P4 (Table 1). The amount of methylene blue concentration absorbed was directly proportional to the surface area of activated carbon, but it can't distinguish the absorptions between micropore and mesopore levels. The methylene blue absorption test on activated carbon showed the same trend for P3 and $\mathrm{P} 4$ activation sequences. The treatment with phosphoric acid solutiona, as activating agent, have produced activated carbon with very large surface area. These results are identical with Ip et al [8] dan Cheung et al [9].The acid activation before and after carbonization showed identical results in surface area. The P3 activation sequencesgave larger pore diameter than P4 (Table 2). In Figure 2 (a), the $\mathrm{N}_{2}$ adsorption and desorption isotherms profile showed a small and constantly adsorptive volume at various pressures [17], which has a confirmation of micropore presence without significant mesopore in activated carbon. The unusual $\mathrm{N}_{2}$ physisorption pattern confirmed an adsorption hysteresis, which according to IUPAC isotherm classification standard, has been associated with capillary condensation inside pore structure [16]. The $\mathrm{N}_{2}$ physisorption pattern in observed in Figure 2 (a) refers to Type $\mathrm{H} 4$ of the classification, which is usually associated with narrow slit-like pores.

The pore distribution in Figure 2 (b) showed the tendency for mesoporous formation of activated carbon structures. Activated carbon, produced in the P3 activation sequences, had almost the same micropore and mesopore volumes as indicated by the $0.015 \mathrm{~cm}^{3} / \mathrm{g}$ micropore volume and $0.009 \mathrm{~cm}^{3} / \mathrm{g}$ mesopore volume. The P3 activation sequences gave $93.71 \%$ mesoporous distribution,

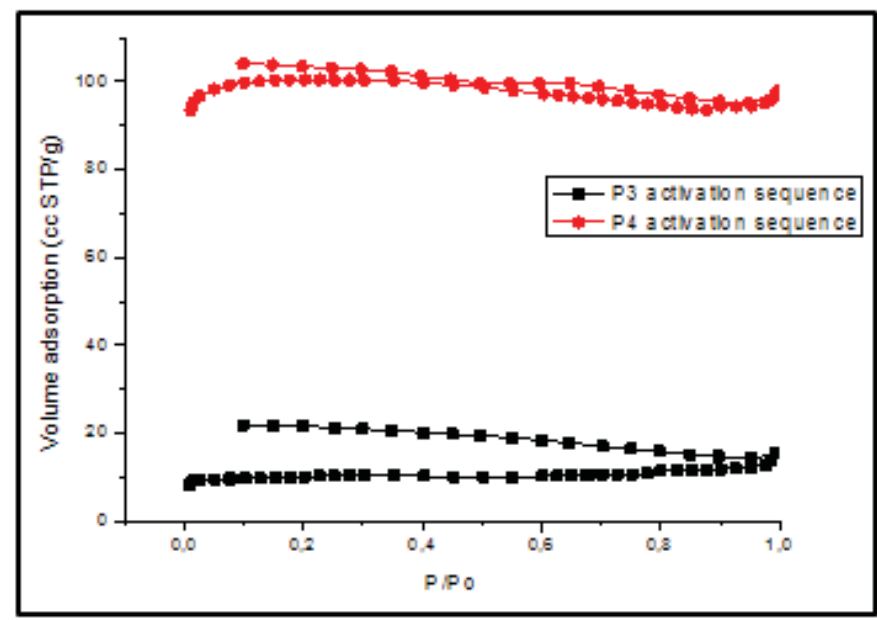

(a)

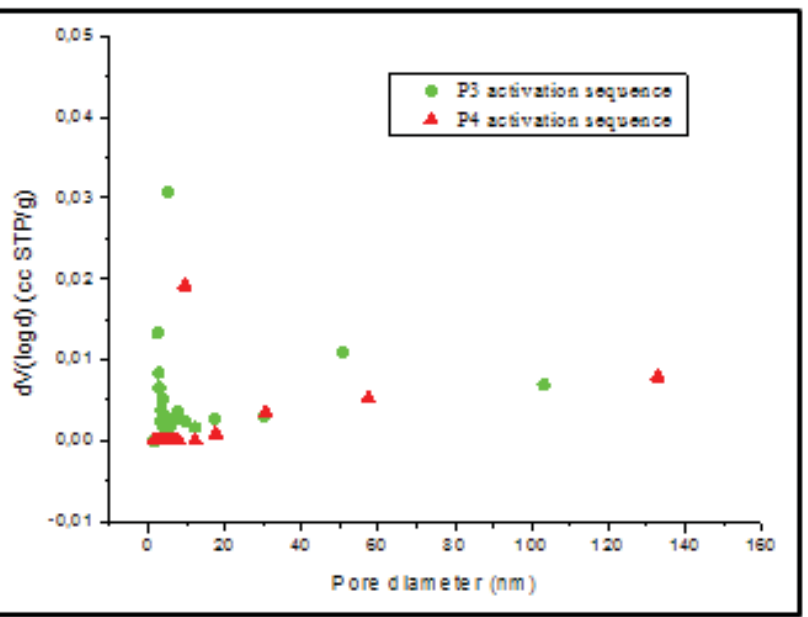

(b)

Figure 2: Profile of isotherm $\mathrm{N}_{2}$ at $77 \mathrm{~K}$ (a) dan $\mathrm{BJH}$ adsorption pore size distribution (b) for activated carbon synthesis in $\mathrm{P} 3$ and $\mathrm{P} 4$ activation sequence 
greater than the P4 activation sequences (78.42\%). The bamboo carbon has a weaker structure, which makes the pore enlargement easier when activated by acids. Acid activation in bamboo is less efficient because bamboo still has a dense structure with few pores, making the penetration of acid solution more difficult. According to the last results, $\mathrm{Fe}-\mathrm{Co} / \mathrm{activated}$ carbon catalysts will be synthezised from P3 and P4 activation sequences activated carbon to compare the material properties.

The crystal structure of activated carbon was analyzed using XRD (X-Ray Diffraction). The activated carbon profile in XRD analysis in various activation sequencewas shown in Figure 3. The XRD spectra pattern of activated carbon was identical to the XRD spectra pattern of activated carbon results of the Fu et al study [5] that used as a standard with sharp peaks occurring at $2 \theta$ diffraction angle at below $10^{\circ}$ and the top of the ramps was at

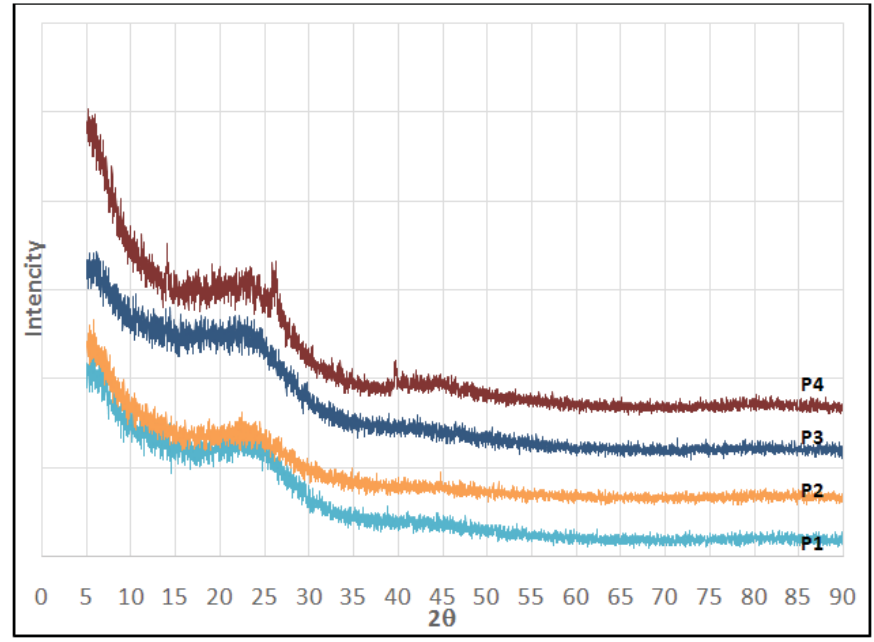

Figure 3: XRD Spectra of bamboo activated carbon in various activation sequencesof $P 1, P 2, P 3$ and $P 4$

Table 1: Comparison of methylene blue adsorption and BET analysis in various carbon activation sequences (initial methylene blue was 20 ppm)

\begin{tabular}{|c|c|c|c|c|}
\hline $\begin{array}{c}\text { Activation } \\
\text { Sequence }\end{array}$ & Absorbance & $\begin{array}{c}\text { Methylene } \\
\text { BlueAdsorbed } \\
(\mathbf{p p m})\end{array}$ & $\begin{array}{c}\text { Methylene } \\
\text { BlueAdsorbed } \\
(\%)\end{array}$ & $\begin{array}{c}\mathbf{S}_{\mathrm{BET}} \\
\left(\mathbf{m}^{2} / \mathbf{g}\right)\end{array}$ \\
\hline P1 & 0.942 & 4.8065 & 24.03 & 477.964 \\
\hline P2 & 0.957 & 4.5645 & 22.83 & 427.042 \\
\hline P3 & 0.041 & 19.3387 & 96.69 & 2173.000 \\
\hline P4 & 0.070 & 18.8710 & 94.36 & 2091.525 \\
\hline
\end{tabular}

Table 2: The surface properties of bamboo activated carbon from $P 3$ and $P 4$ activation sequences using full isotherm BET analysis

\begin{tabular}{|c|c|c|c|c|c|}
\hline $\begin{array}{c}\text { Activation } \\
\text { Sequence }\end{array}$ & $\begin{array}{c}\mathbf{S}_{\text {total }} \\
\mathbf{m}^{2} / \mathbf{g}\end{array}$ & $\begin{array}{c}\mathbf{V}_{\text {total }} \\
\mathbf{c m}^{3} / \mathbf{g}\end{array}$ & $\begin{array}{c}\mathbf{V}_{\text {micro }} \\
\mathbf{c m}^{3} / \mathbf{g}\end{array}$ & $\begin{array}{c}\mathbf{V}_{\text {meso }} \\
\mathbf{c m}^{3} / \mathbf{g}\end{array}$ & $\begin{array}{c}\mathbf{d}_{\text {average }} \\
\mathbf{n m}\end{array}$ \\
\hline $\mathrm{P} 3$ & 2173 & 0.02402 & 0.015 & 0.00902 & 15.4107 \\
\hline $\mathrm{P} 4$ & 2091 & 0.1514 & 0.149 & 0.0024 & 10.1103 \\
\hline
\end{tabular}

$2 \theta$ diffraction angle between $20^{\circ}$ and $25^{\circ}$. The activated carbon from various activation sequences had an identical XRD profile and showed typical spectra for activated carbon.

\section{Functionalization}

The functionalization process formed oxygen group on the activated carbon surface as active sites during catalyst impregnation. The oxygen functional group after functionalization were detected by FTIR analysis (Figure 4). Groups of O-H carboxylic, O-H alcohol and phenol were presented before the functionalization process because the phosphoric acid activation might form functional groups even though small. The presence of the carbonyl $\mathrm{C}=\mathrm{O}$ carboxylic group in post-functionalization confirmed oxygen functional group presence as carboxylic acid. Comparison of FTIR spectra before and after functionalization was carried out on activated carbon of $\mathrm{P} 4$ activation sequence. According to Figure 4, O-H phenol and $\mathrm{O}-\mathrm{H}$ carboxylic groups had been found in spectra in relatively small area and getting bigger after functionalization. The presence of $\mathrm{C}=\mathrm{O}$ carbonyl emphasized the presence of carboxylic groups on activated carbon surface. The P3 and P4 sequences activated carbon showed that the carboxylic and phenol groups were much larger than $\mathrm{P} 1$ and $\mathrm{P} 2$. The small surface area at $\mathrm{P} 1$ and P2 (as shown by the BET analysis results) influenced at least the functional groups formed. A small surface area will provide a small active site so that the functional groups formed were limited in this condition. The very large surface area in P3 and P4 provided large functional groups. The comparison of P3 and P4 activation sequences gave identical spectra but they had different area of the $\mathrm{C}=\mathrm{O}$ carbonyl group. The $\mathrm{P} 4$ had greater area of the carboxylic $\mathrm{O}-\mathrm{H}$ and $\mathrm{O}-\mathrm{H}$ phenol groups. From the results of this FTIR analysis, the P4 activation sequences gave better results because more functional groups were formed than the other activation sequences.

\section{The effect of physical activation and material size}

Physical activation was carried out to functionalized activated carbon before it applied to impregnation process. 
Activated carbon before and after physical activation at $700^{\circ} \mathrm{C}$ were analyzed with FTIR. The $700^{\circ} \mathrm{C}$ physical activation in atmospheric flowing nitrogen destroyed oxy-

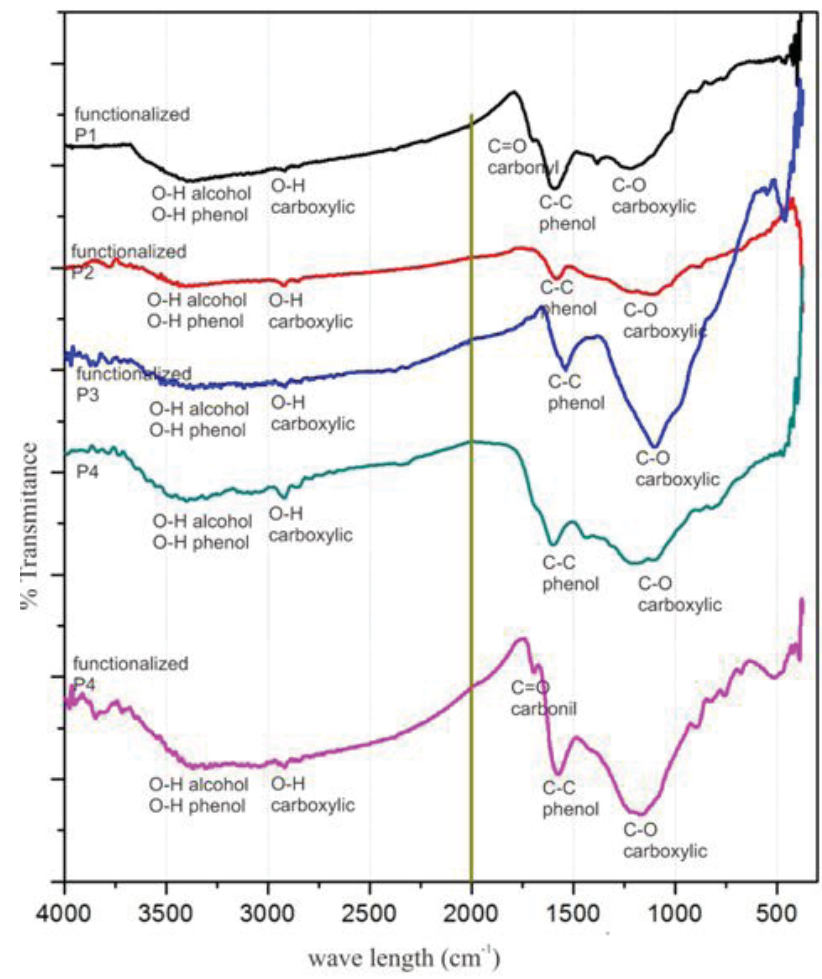

Figure 4: FTIR analysis of functionalized activated carbon in various activation sequence and Comparison of FTIR spectra before and after functionalization in P4 activation sequences gen function groups that had formed during functionalization. Figure 5 showed that some oxygen groups had been formed on the surface of activated carbon before physical activation. Nitric acid is a strong oxidizing agent, it oxidized carbon atoms so that carbon losed electrons and becomes positively charged so that carbon attracted anions such as oxygen molecules to form oxide groups. The lower amount of functional groups was formed after the physical activation, because the physical activation eliminated the existing functional groups $(\mathrm{C}=\mathrm{O}$ carbon$\mathrm{yl}$ ) and reduced the functional groups quantity that have formed (carboxylic O-H).

The size of activated carbon material did not have a significant effect on the presence of oxygen groups formed. Figure 5 shows that both the activated carbon powder and the Raschig rings produced the same type of functional group (carboxylic group and alcohol). According to the area formed, powder activated carbon gave more functional group quantities than the Raschig rings. The surface of powder activated carbon was more easily accessed by nitric acid as a strong oxidizing agent was used as functional agent thereby increasing the chance of forming oxygen functional groups on the catalyst active site.

\section{Impregnation}

Surface area changing after $\mathrm{Fe}$ and $\mathrm{Co}$ impregnation on activated carbon could be seen in Table 3. A significant decrease in surface area (more than $50 \%$ ) was caused by the pore radius of activated carbon being small enough $(1-1.5 \mathrm{~nm})$ so that it was covered by large metal

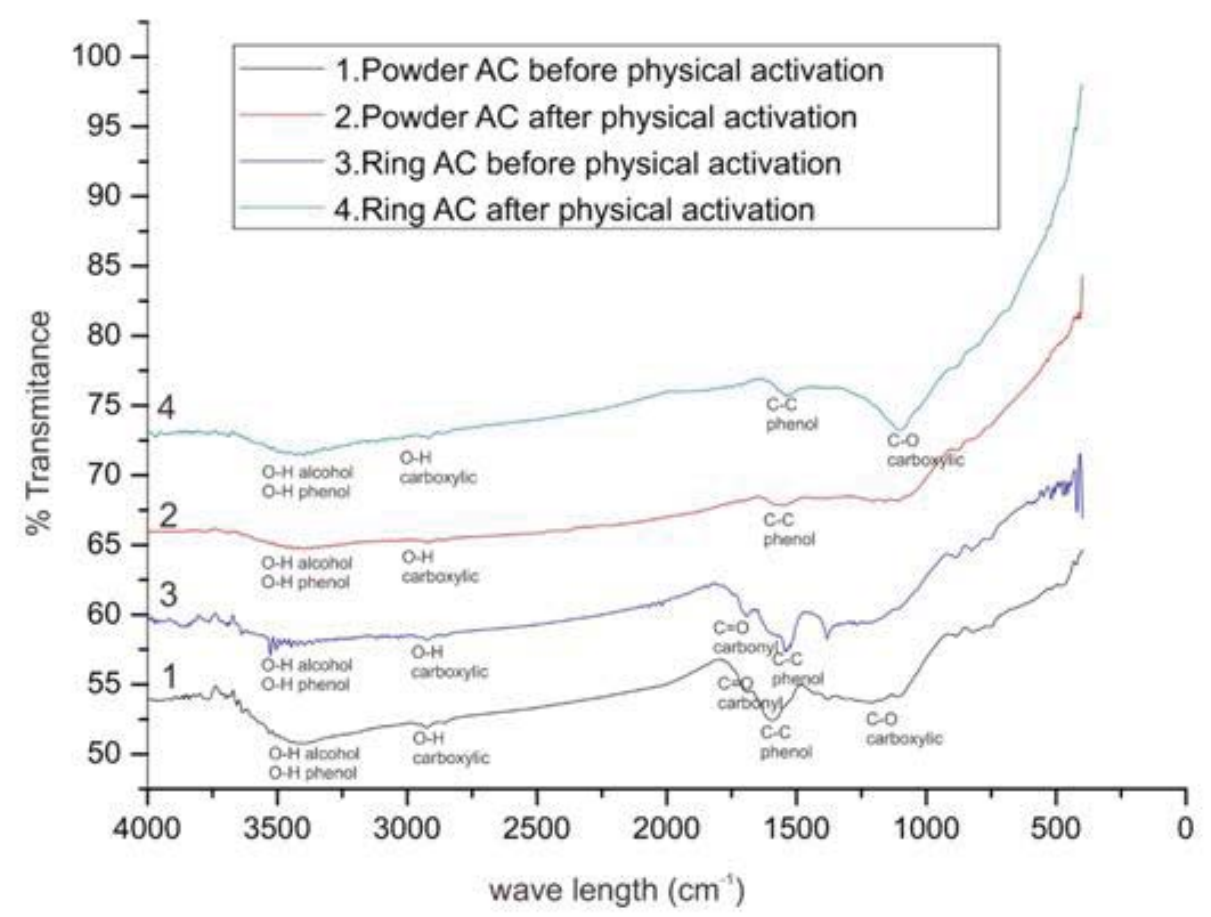

Figure 5: The effect of physical activation $\left(700^{\circ} \mathrm{C}\right.$ for 2 hours) for functionalized activated carbon in powder and ring with FTIR analysis 
oxides. A perfect reduction will produce small Fe and Co free metals to enter the active carbon pore $(\mathrm{Fe}=0.126$ $\mathrm{nm}$; Co $=0.125 \mathrm{~nm}$ ). The Fe and Co impregnated on ring activated carbon were very small compared to on powder, so that powder activated carbon was used in the next step in various catalyst composition $(0,10,20,30$, $40 \% \mathrm{Fe}$ in Fe-Co). Table 4 showed the Fe-Co impregnated that were obtained from impregnation process. The Fe and Co impregnated were about $25-60 \%$ from their weight in precursor solution. This indicated that $\mathrm{Fe}$ and Co were not impregnated homogeneously on overall HZSM-5 surface area. The metal composition obtained

Table 3:The effect of activation sequence to surface area of activated carbon before and after catalyst impregnation (loading 10\%, OFe-100Co/Activated Carbon)

\begin{tabular}{|c|c|c|}
\hline \multirow{2}{*}{$\begin{array}{c}\text { Activation } \\
\text { Sequence }\end{array}$} & \multicolumn{2}{|c|}{ Surface Area $\left(\mathbf{m}^{2} \mathbf{l g}\right)$} \\
\cline { 2 - 3 } & $\begin{array}{c}\text { Before } \\
\text { Impregnation }\end{array}$ & $\begin{array}{c}\text { After } \\
\text { Impregnation }\end{array}$ \\
\hline P3 & 2173 & 807 \\
\hline P4 & 2091 & 791 \\
\hline
\end{tabular}

after impregnation were similar to Fe and Co from initial precursor solution.

The P3 and P4 activated carbon was reduced and analyzed with XRD (Figure 6). According to XRD database from Tavasoli et al [18], carbon spectrum were at $25^{\circ}$ dan $43^{\circ}$. Simultaneous iron and cobalt impregnation formed alloy of Fe-Co which have spectrum of $45^{\circ}, 53^{\circ}$ and $62^{\circ}$. Figure 6 showed XRD spectrum of Fe-Co alloys in $10 \mathrm{Fe}$ $90 \mathrm{Co} / a c t i v a t e d$ carbon, even though the peak formed was relatively small. The presence of Co was also shown in $44^{\circ}$ and $77^{\circ}$ while $\mathrm{Fe}$ was not found in the XRD spectrum. The $10 \% \mathrm{Fe}$ had been attached to $90 \%$ Co to form Fe-Co alloys, so that it is no longer found in final catalyst. The nitric form of precursor had been converted into oxide form in calcination process The presence of $\mathrm{Fe}_{2} \mathrm{O}_{3}$ and $\mathrm{Co}_{3} \mathrm{O}_{4}$ oxides after reduction indicated that the oxide form of iron and cobalt were not reduced thoroughly into Fe and Co.

The XRD spectra of reduced impregnated metal catalyst on the powder activated carbon (AC) could been seen in Figure 7. The Fe-Co alloysin $\mathrm{Fe}-\mathrm{Co} / \mathrm{AC}$ catalyst were found in all catalyst materials. The presence of $\mathrm{Fe}_{2} \mathrm{O}_{3}$ and $\mathrm{Co}_{3} \mathrm{O}_{4}$ content in this catalyst showed that the process of reducing oxide compounds to metals had

Table 4: The impregnated iron and cobalt on powder activated carbon in various iron composition in Fe-Co mixtures (EDX analysis)

\begin{tabular}{|c|c|c|c|c|c|c|c|}
\hline \multirow{3}{*}{$\begin{array}{c}\text { Fe-Co } \\
\text { Composition }\end{array}$} & \multicolumn{6}{|c|}{ Impregnation } & \multirow{3}{*}{$\begin{array}{l}\text { Imregnated } \\
\mathrm{Fe} \text { in } \\
\mathrm{Fe}-\mathrm{Co}(\%)\end{array}$} \\
\hline & \multicolumn{3}{|c|}{ Metal weight in solutions (g) } & \multicolumn{3}{|c|}{$\begin{array}{l}\text { Impregnated Metal Weight } \\
\text { (g) }\end{array}$} & \\
\hline & $\mathrm{Fe}$ & Co & Fe-Co & $\mathrm{Fe}$ & Co & Fe-Co & \\
\hline OFe-100Co & 0 & 0.40 & 0.40 & 0 & 0.198 & 0.198 & 0 \\
\hline 10Fe-90Co & 0.04 & 0.36 & 0.4 & 0.009 & 0.097 & 0.106 & 8.90 \\
\hline 20Fe-80Co & 0.08 & 0.32 & 0.4 & 0.033 & 0.120 & 0.152 & 21.46 \\
\hline 30Fe-70Co & 0.12 & 0.28 & 0.4 & 0.038 & 0.128 & 0.165 & 22.72 \\
\hline 40Fe-60Co & 0.16 & 0.24 & 0.4 & 0.130 & 0.124 & 0.254 & 51.12 \\
\hline
\end{tabular}

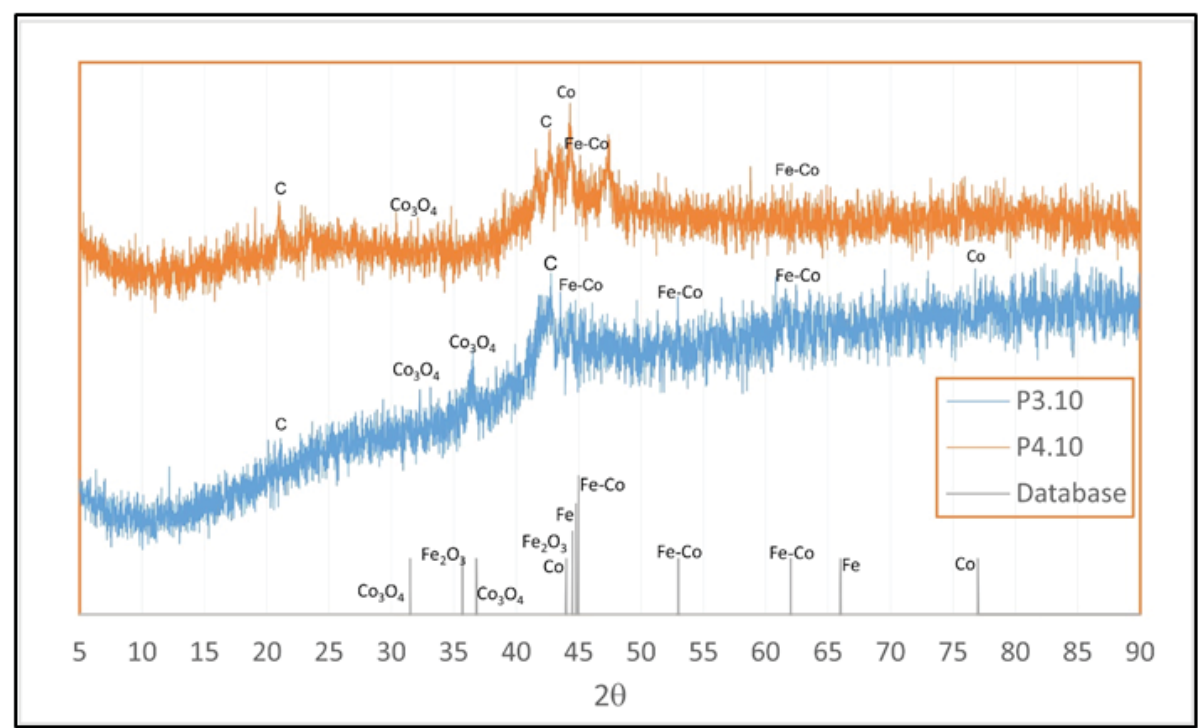

Figure 6: The effect of activation sequences ( $P 3$ and $P 4)$ to reduction process for impregnated iron and cobalt on activated carbon (10Fe-90Co/Activated Carbon) with XRD analysis 
not been running properly. The larger amount of Fe-Co alloys were formed on 30Fe-70Co/AC and 40Fe-60Co/ $\mathrm{AC}$ catalyst. The similar composition of $\mathrm{Fe}$ and $\mathrm{Co}$ gave sufficient amounts for the formation of more Fe-Co alloys compared to other composition. The $\mathrm{Fe}_{2} \mathrm{O}_{3}$ and $\mathrm{Co}_{3} \mathrm{O}_{4}$ oxides could not be found on both catalyst. The catalyst of 0Fe-100Co/AC, 10Fe-90Co/AC, 20Fe-80Co/AC still left a large amount of Co-free metal.

\section{Catalyst performance in a batch Fischer-Tropsch synthesis}

Fischer-Tropsch synthesis is a reaction between $\mathrm{H}_{2}$ and $\mathrm{CO}$ with $\mathrm{Fe}$ and $\mathrm{Co}$ metal catalyst to produce long chain hydrocarbons (wax). Combining the two metal catalysts with activated carbon (Fe-Co/AC) as a support is expected to produce short chain hydrocarbons as biofuel fraction. For initial catalyst performance test, the reaction was carried out with 2 gram catalyst in batch reactor at $250^{\circ} \mathrm{C}$ and 8 bars for 18 hours. Fischer-Tropsch synthesis produced 2 products in gas and liquid phase. Several groups of compounds were detected through
GCMS analysis. The relationship between the resulting liquid composition with the composition of $\mathrm{Fe}-\mathrm{Co}$ in the catalyst was presented in Figure 8. The Fischer-Tropsch synthesis produced bit liquid fraction in 0Fe-100Co/ $\mathrm{AC}$ and $30 \mathrm{Fe}-70 \mathrm{Co} / \mathrm{AC}$ catalysts then they were not enough for analyzing. The liquid fraction produced from Fischer-Tropsch synthesis using catalysts $10 \mathrm{Fe}-90 \mathrm{Co} /$ $\mathrm{AC}, 20 \mathrm{Fe}-80 \mathrm{Co} / \mathrm{AC}$ and $40 \mathrm{Fe}-60 \mathrm{Co} / \mathrm{AC}$ was dominated by aromatic compounds compared to n-paraffin compounds which are the main target in biofuel production. The n-paraffin compound is only formed in 40Fe-60Co/ AC catalyst which contained the most Fe-Co alloys. The more Fe-Co alloys content was, more n-paraffin was formed. The n-paraffin $(\mathrm{OH})$ compound was only formed in $10 \mathrm{Fe}-90 \mathrm{Co} / \mathrm{AC}$. The more Co content was, more n-paraffin $(\mathrm{OH})$ was formed.

\section{CONCLUSION}

The carbonization-acid (P3) and acid-carbonization (P4) activation sequences showed identical surface area results. The best activated carbon was obtained from the P3 activation sequence with a surface area of $2173 \mathrm{~m}^{2} / \mathrm{g}$.

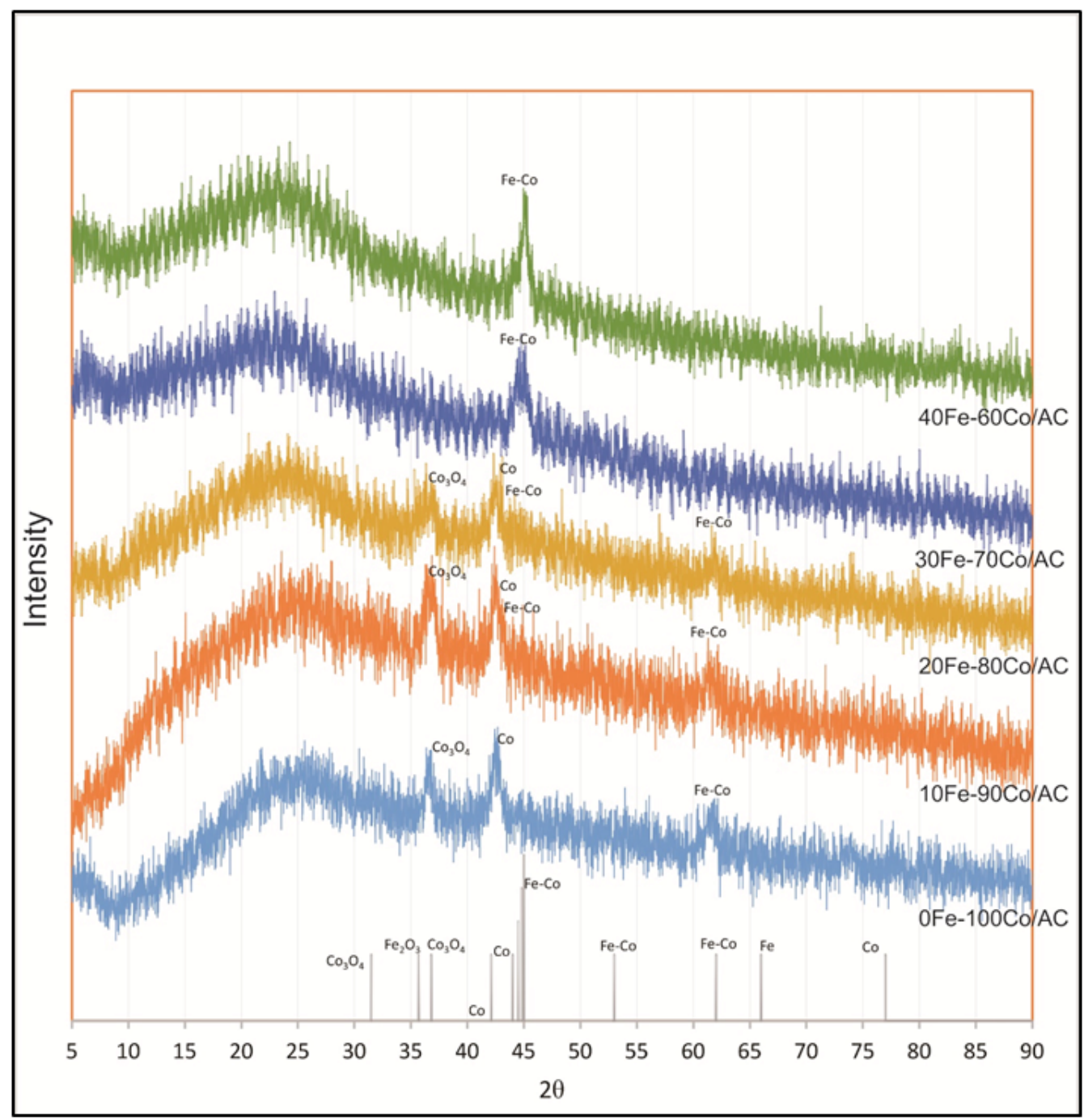

Figure 7: The XRD spectra of reduced impregnated metal catalyst on the powder activated carbon in various iron composition in Fe-Co/Activated Carbon 


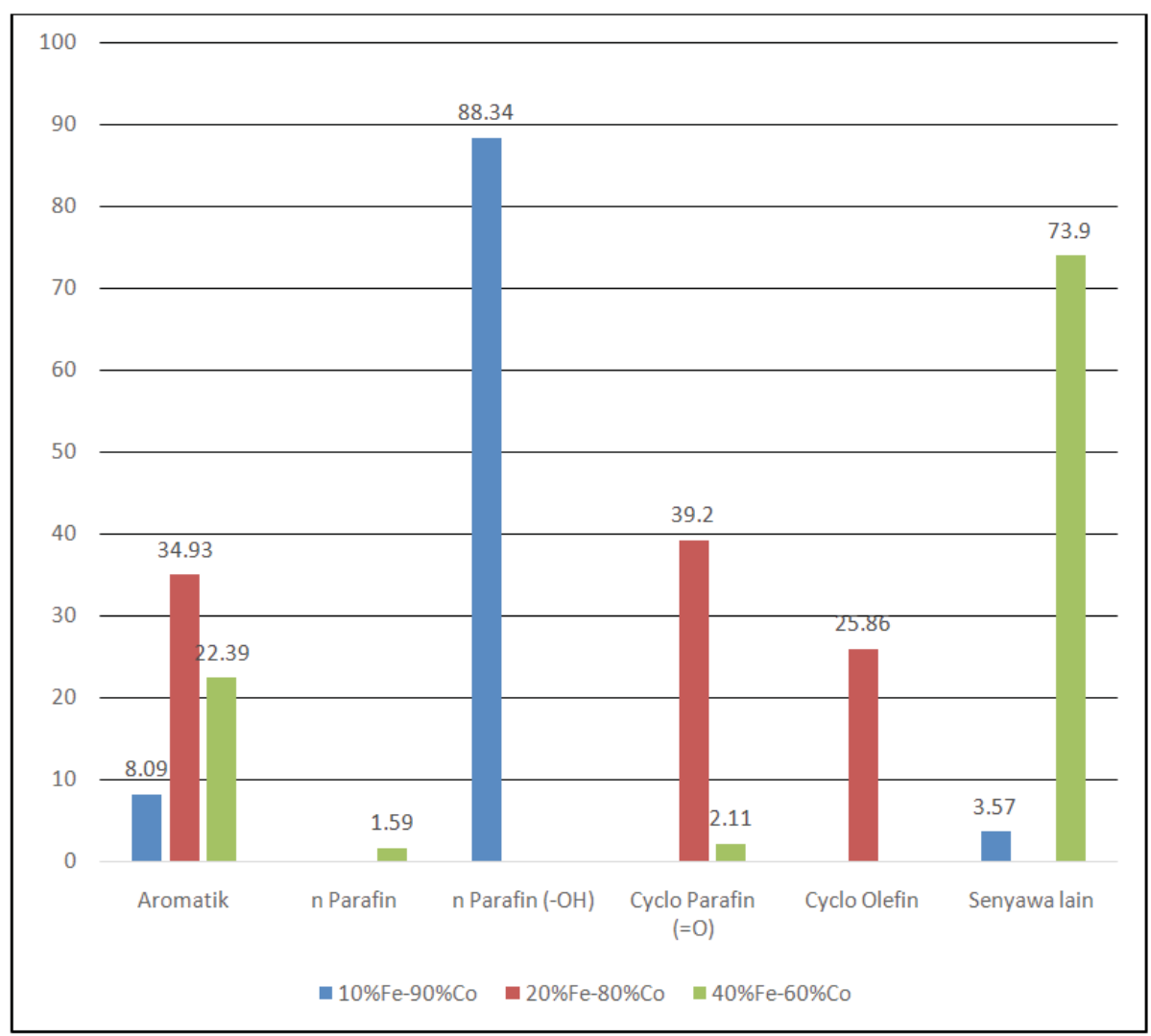

Figure 8: The liquid product composition in various Fe-Co/A Cin batch reactor. The reaction was carried out with $2 \mathrm{~g}$ catalyst in batch reactor at $250^{\circ} \mathrm{C}, 8$ bars for 18 hours

$\mathrm{P} 4$ sequence had larger surface area of $\mathrm{O}-\mathrm{H}$ carboxylic and $\mathrm{O}-\mathrm{H}$ phenol.

The functional groups formed after the physical activation were reduced because the $700^{\circ} \mathrm{C}$ physical activation eliminated the existing functional groups $(\mathrm{C}=\mathrm{O}$ carbon$\mathrm{yl})$ and reduce the functional groups quantity that have formed (O-H carboxylic).

The size of activated carbon material did not have a significant effect on the presence of oxygen groups formed.

The larger amount of Fe-Co alloys were formed on 30Fe70Co/Activated Carbon and 40Fe-60Co/Activated Carbon catalyst. The $\mathrm{Fe}_{2} \mathrm{O}_{3}$ and $\mathrm{Co}_{3} \mathrm{O}_{4}$ oxides could not be found on both catalyst.

The n-paraffin compound is only formed in $40 \mathrm{Fe}-60 \mathrm{Co} /$ AC catalyst which contained the most Fe-Co alloys. The more Fe-Co alloys content was, more n-paraffin was formed. The n-paraffin $(\mathrm{OH})$ compound was only formed in $10 \mathrm{Fe}-90 \mathrm{Co} / \mathrm{AC}$. The more Co content was, more $\mathrm{n}$-paraffin $(\mathrm{OH})$ was formed.

\section{REFERENCES}

1. van der Laan GP, Laan GP Van Der, van der Laan GP (1999). Kinetics, Selectivity and Scale Up of the Fischer-Tropsch Synthesis

2. Dalai AK, Davis BH (2008). Fischer-Tropsch synthesis: A review of water effects on the performances of unsupported and supported Co catalysts. Applied Catalysis A: General 348:1-15. https://doi. org/10.1016/j.apcata.2008.06.021
3. Bezemer GL, Radstake PB, Falke U, et al (2006). Investigation of promoter effects of manganese oxide on carbon nanofiber-supported cobalt catalysts for Fischer-Tropsch synthesis. Journal of Catalysis 237:152-161. https://doi.org/10.1016/j. jcat.2005.10.031

4. Surisetty VR, Dalai AK, Kozinski J (2010). Synthesis of higher alcohols from synthesis gas over Co-promoted alkali-modified MoS2 catalysts supported on MWCNTs. Applied Catalysis A: General. https://doi. org/10.1016/j.apcata.2010.07.009

5. Fu T, Jiang Y, Lv J, Li Z (2013). Effect of Carbon Support on Fischer-Tropsch Synthesis Activity and Product Distribution over Co-Based Catalysts. Fuel Processing Technology 110:141-149. https://doi. org/10.1016/j.fuproc.2012.12.006

6. Asma IW, Rafidah J, Puad E, Shaharuddin H (2011). Production of Activated Carbon from Industrial Bamboo Wastes. 23:417-424

7. Liu Y, Luo J, Girleanu M, et al (2014). Efficient hierarchically structured composites containing cobalt catalyst for clean synthetic fuel production from Fischer-Tropsch synthesis. Journal of $\mathrm{Ca}$ talysis 318:179-192. https://doi.org/10.1016/j. jcat.2014.08.006

8. Ip AWM, Barford JP, McKay G (2008). Production and comparison of high surface area bamboo derived active carbons. Bioresource Technology 99:89098916. https://doi.org/10.1016/j.biortech.2008.04.076 
9. Cheung WH, Chan LS, Lau KST, et al (2006). Production of High Surface Area Activated Carbons from Waste Bamboo Scaffolding. 1-22

10. Cheung WH, Lau SSY, Leung SY, et al (2012). Characteristics of Chemical Modified Activated Carbons from Bamboo Scaffolding. 20:515-523

11. Figueiredo JL, Serp P (2009). Carbon Material for Catalysis. John Wiley \& Sons, Inc, Hobokem New Jersey

12. Mukenz TM Fischer-Tropsch Reaction: Towards Understanding The Mixed Iron-Cobalt Catalyst Systems. 2010:

13. Ali S, Mohd Zabidi N, Subbarao D (2011). Correlation between Fischer-Tropsch catalytic activity and composition of catalysts. Chemistry Central Journal 5:68. https://doi.org/10.1186/1752-153X-5-68

14. Mansouri M, Atashi H (2016). Fischer-tropsch synthesis over potassium-promoted $\mathrm{Co}-\mathrm{Fe} / \mathrm{SiO}_{2}</$ inf $>$ catalyst. Indian Journal of Chemical Technology

15. Lippens BC, de Boer JH (1965). Studies on pore systems in catalysts. V. The t method. Journal of Catalysis. https://doi.org/10.1016/0021-9517(65)90307-6

16. Barrett EP, Joyner LG, Halenda PP (1951). The Determination of Pore Volume and Area Distributions in Porous Substances. I. Computations from Nitrogen Isotherms. Journal of the American Chemical Society. https://doi.org/10.1021/ja01145a126
17. Nunes CA, Guerreiro MC (2011). Estimation of surface area and pore volume of activated carbons by methylene blue and iodine numbers. Quimica Nova. https://doi.org/10.1590/S0100-40422011000300020

18. Tavasoli A, Trépanier M, Malek Abbaslou RM, et al (2009). Fischer-Tropsch synthesis on mono- and bimetallic $\mathrm{Co}$ and Fe catalysts supported on carbon nanotubes. Fuel Processing Technology. https://doi. org/10.1016/j.fuproc.2009.07.007 